\title{
Impact of Gastrointestinal In Vitro Digestion and Deficit Irrigation on Antioxidant Activity and Phenolic Content Bioaccessibility of "Manzanilla" Table Olives
}

\author{
Lucía Sánchez-Rodríguez, ${ }^{1}$ Marina Cano-Lamadrid ${ }^{(D)},{ }^{2}$ Ángel A. Carbonell-Barrachina (iD, ${ }^{1}$ \\ Francisca Hernández, ${ }^{2}$ and Esther Sendra ${ }^{3}$ \\ ${ }^{1}$ Departamento de Tecnología Agroalimentaria, Grupo de Calidad y Seguridad Alimentaria, \\ Escuela Politécnica Superior de Orihuela, Universidad Miguel Hernéndez de Elche, Carretera de Beniel, km 3.2, Orihuela 03312, \\ Alicante, Spain \\ ${ }^{2}$ Departamento de Producción Vegetal y Microbiología, Grupo Producción Vegetal, Escuela Politécnica Superior de Orihuela, \\ Universidad Miguel Hernández de Elche, Carretera de Beniel, Km 3.2, 03312-Orihuela, Alicante, Spain \\ ${ }^{3}$ Departamento de Tecnología Agroalimentaria, Grupo de Calidad y Seguridad Alimentaria, \\ Escuela Politécnica Superior de Orihuela, Universidad Miguel Hernéndez de Elche, Carretera de Beniel, km 3.2, Orihuela 03312, \\ Alicante, Spain
}

Correspondence should be addressed to Ángel A. Carbonell-Barrachina; angel.carbonell@umh.es

Received 18 December 2019; Revised 18 February 2020; Accepted 2 March 2020; Published 1 April 2020

Academic Editor: Flora V. Romeo

Copyright (C) 2020 Lucía Sánchez-Rodríguez et al. This is an open access article distributed under the Creative Commons Attribution License, which permits unrestricted use, distribution, and reproduction in any medium, provided the original work is properly cited.

\begin{abstract}
This was the first study investigating the polyphenol content, antioxidant potential, and polyphenol bioaccessibility after in vitro digestion of table olives grown using regulated deficit irrigation (RDI) treatments to save irrigation water. Two experiments were carried out: (i) experiment A, where RDI was applied during the pit hardening stage and (ii) experiment B, where RDI was applied during the rehydration stage. Only slight differences among irrigation treatments were observed in two antioxidant assays $\left(\mathrm{ABTS}^{+}{ }^{\bullet}\right.$ and $\mathrm{DPPH}^{\bullet}$ ) and on TPC for the soluble fraction after in vitro digestion. An average of $1 \mathrm{~g}$ gallic acid equivalents $\mathrm{kg}^{-1} \mathrm{of}^{-}$ table olives were found after digestion. Approximately, $12 \%$ of the polyphenols of table olives were bioaccessible for human absorption. Saving water techniques influence neither the final polyphenol content and antioxidant potential of table olives nor the bioaccessibility of polyphenols. The consumption of $40 \mathrm{~g}$ of table olives will provide $40 \mathrm{mg}$ of bioaccessible polyphenols able to provide associated health benefits ( $\sim 7 \%$ of the daily polyphenols intake recommendation).
\end{abstract}

\section{Introduction}

Table olives are a common constituent of Mediterranean diet and have beneficial effects on human health because they are antioxidant-rich foods [1]. Olives are rich in polyphenols (1$2 \%$ of its composition), and these compounds provide antioxidant, anti-inflamatory, and antitumoral properties to table olives. Olive composition can be affected by several factors such as climate, agronomic conditions, and the processing method. [2]. Nowadays, regulated deficit irrigation (RDI) strategies are being implemented on olive tree orchards with the main purpose of saving water. Additionally, moderate RDI strategies are being investigated in table olives due to their "potential" effect on enhancing the accumulation of bioactive compounds and improvement of the intensity of key sensory attributes; these special table olives are known as hydroSOStainable [3].

Studying the bioaccessibility of antioxidant and polyphenolic compounds is crucial to know their real behavior and activity in vivo. Bioaccessibility is defined as the tendency of compounds to be extracted from the food matrix and then, be available for intestinal cell absorption [1]. For that purpose, gastrointestinal in vitro digestion simulation is a model to extract compounds from the test matrix simulating human digestion, and although it is important to consider that several factors (gender, age, intestinal 
conditions, etc.) will affect digestion, this model is still a good alternative to avoid animal testing methods and promote animal protection [4].

In the present research, "Manzanilla" Spanish-style table olives grown under different RDI strategies (experiment A: water irrigation was reduced during the pit hardening stage; experiment B: water irrigation was reduced during the rehydration stage) were subjected to a gastrointestinal in vitro digestion simulation with the purpose to study how the lack of water during cultivation affects the polyphenol content, polyphenol bioaccessibility, and antioxidant activity by three methods after simulation of human digestion.

\section{Materials and Methods}

2.1. Experimental Conditions and Irrigation Treatments. Two irrigation experiments were carried out in this study on cultivar "Manzanilla" to evaluate the effect of water stress at two phenological stages:

\subsubsection{Experiment $A$}

(i) A0 (optimum water status): trees were fully irrigated

(ii) A1 (moderate deficit irrigation): the threshold value for water stress level $\left(\psi_{\text {stem }}\right)$ was $-2 \mathrm{MPa}$ during the pit hardening stage (day of the year (DOY) 169 to DOY 240)

(iii) A2 (severe deficit irrigation (short time)): the threshold value for $\psi_{\text {stem }}$ was $-3 \mathrm{MPa}$ during half period of the pit hardening stage (from DOY 169 to DOY 206)

(iv) A3 (severe deficit irrigation (long time)): the threshold value for $\psi_{\text {stem }}$ was $-3 \mathrm{MPa}$ until end of period of the pit hardening stage (DOY 169 to DOY 240)

\subsubsection{Experiment $B$}

(i) B0 (optimum water status): trees were fully irrigated

(ii) B1 (moderate deficit irrigation before harvest (short time)): the threshold value for $\psi_{\text {stem }}$ was $-2 \mathrm{MPa}$ at the beginning of September without the rehydration period ( 2 weeks before harvest)

(iii) B2 (moderate deficit irrigation (long time)): the threshold value for $\psi_{\text {stem }}$ was $-2 \mathrm{MPa}$ from midAugust without the rehydration period (four weeks before harvest)

Experiment A was carried out in a farm located in Dos Hermanas (Seville, Spain, $37^{\circ} 25^{\prime} \mathrm{N}, 5^{\circ} 95^{\prime} \mathrm{W}$ ). "Manzanilla" olive trees were $\sim 30$ years old and were spacing following a $7 \times 4$ square pattern. Irrigation was performed at night by drip with one lateral pipe per row of trees and four emitters (each delivering $2 \mathrm{~L} \mathrm{~h}^{-1}$ ) per plant.

With respect to experiment $\mathrm{B}$, the farm was located in Coria del Río (Seville, Spain, $37^{\circ} 17^{\prime} \mathrm{N}, 6^{\circ} 3^{\prime} \mathrm{W}$ ). "Manzanilla" olive trees were $\sim 44$ years old and were spacing following a $7 \times 5 \mathrm{~m}$ square pattern. Also, irrigation was carried out during night by one lateral pipe per tree row and five emitters (each delivering $8 \mathrm{Lh}^{-1}$ ) per plant. Specific agronomy characteristics could be found in [5]. Different locations were used because of land availability, although, as explained before, similar conditions characterized the field and weather.

Field characteristics of both experiments could be found in the work by Sánchez-Rodríguez and Cano-Lamadrid et al. [3]. Climatic conditions could be considered equal for both experiments because only $10 \mathrm{~km}$ separated the farms. A total rainfall amount of $258.94 \mathrm{~mm}$ was registered on experiment A from 3 September 2015 to 20 September 2016, while $254,25 \mathrm{~mm}$ of total rainfall amount on experiment B from 8 September 2015 to 27 September 2016. Winter minimum temperatures were around $0^{\circ} \mathrm{C}$, and spring temperatures determine flowering around mid-April. Pest control, pruning, and fertilization practices were those commonly used by growers.

Stress integral $\left(\Psi_{\text {int }}\right)$ was calculated to study the accumulative stress of olive trees produced du to reduction of water irrigation [6].

$$
\Psi_{\text {int }}=\left|\left(\sum \Psi-(-0.2)\right) \times n\right|
$$

where $\Psi_{\text {int }}$ is the stress integral, $\Psi$ is the average midday stem water potential for any interval, and $n$ is the number of days of the interval.

Olives were collected by hand at their mature-green stage on September 2016.

2.2. "Spanish-Style" Processing. Raw olives were processed following "Spanish-Style" to table olives as previous described in [7]. Briefly, raw olives were treated with $\mathrm{NaOH}$ solution (1.3-2.6\% weight:volume) for 6-8h with the purpose to remove oleuropein, and then, olives were washed with water for $12-14 \mathrm{~h}$ to remove residual $\mathrm{NaOH}$. Olives were put on $10-12 \% \mathrm{NaCl}$ solution for fermentation until table olives-brine equilibrium was reached $(\mathrm{pH}<4.2,8-9 \%$ (weight:volume) $\mathrm{NaCl}, 0.7-1.0 \%$ lactic acid and residual alkalinity $<0.120 \mathrm{~N})$.

2.3. Gastrointestinal In Vitro Digestion Simulation. In vitro digestion simulation was carried out following the method described in [8] on table olives of all irrigation treatments under study. Firstly, salivary solution simulation (SSS), gastric solution simulation (GSS), and intestinal solution simulation (ISS) were carried out using $\mathrm{KCl}(0.5 \mathrm{M})$, $\mathrm{KH}_{2} \mathrm{PO}_{4}(0.5 \mathrm{M}), \mathrm{NaHCO}_{3}(1 \mathrm{M}), \mathrm{NaCl}(2 \mathrm{M}), \mathrm{MgCl}_{2}$ $\left(\mathrm{H}_{2} \mathrm{O}\right)_{6}(0.15 \mathrm{M})$, and $\left(\mathrm{NH}_{4}\right)_{2} \mathrm{CO}_{3}(0.5 \mathrm{M})$ following indications in [8]. Simulation of the oral phase was carried out with $10 \mathrm{~g}$ of table olives and simulating mastication with $\alpha$-amylase (1500 $\mathrm{U} \mathrm{mL}^{-1}$ ) (Enzyme Commission (EC) number 3.2.1.1) and SSS. The mixture was placed in a stomacher bag and stomached for 10 minutes to simulate the mastication (Stomacher Laboratory Blender, Bioxia, Thane, India). The resulting mixture was transferred to a glass bottle. Then, the gastric phase was carried out with pepsin $\left(2500 \mathrm{U} \mathrm{mL}^{-1}\right)\left(\mathrm{EC}\right.$ number 3.4.23.1) for $1 \mathrm{~h}$ at $37^{\circ} \mathrm{C}, 170 \mathrm{rpm}$ 
TABle 1: Watering technique conditions of "Manzanilla" table olives of experiment A and experiment B.

\begin{tabular}{lcc}
\hline \multicolumn{3}{c}{ Stress integral (MPa $x$ day) } \\
\hline ANOVA $^{\dagger}$ & Experiment A & $*$ \\
A0 & & $29.6 \mathrm{~b}^{*}$ \\
A1 & & $62.6 \mathrm{ab}$ \\
$\mathrm{A} 2$ & & $50.4 \mathrm{ab}$ \\
$\mathrm{A} 3$ & Experiment B & $87.4 \mathrm{a}$ \\
\hline & & $*$ \\
ANOVA & & $75.7 \mathrm{ab}$ \\
B0 & & $62.9 \mathrm{~b}$ \\
B1 & & $85.5 \mathrm{a}$ \\
\hline
\end{tabular}

${ }^{\dagger *}$ Significant at $p<0.05 .{ }^{*}$ Values followed by the same letter within the same column, and experiment were not significantly different $(p<0.05)$, according to Tukey's least significant difference test.

(Thermostatic bath with agitation BSH, Raypa, Barcelona, España), and pH 3 (adjusted with $\mathrm{HCl}, 6 \mathrm{M}$ ) and GSS. Finally, the intestinal step was performed with ISS, pancreatin $\left(800 \mathrm{U} \mathrm{mL}^{-1}\right)(\mathrm{EC}$ Number 232.468.9), and bile salts $(160 \mathrm{mM})$ at $37^{\circ} \mathrm{C}, 170 \mathrm{rpm}$, and $\mathrm{pH} 7$ (adjusted with $\mathrm{NaOH}$, $1 \mathrm{M})$ for 2 hours. After the intestinal phase, liquid soluble fraction (SF) and solid residual fraction (RF) were collected. The SF was centrifuged at $10,000 \mathrm{rpm}$ for $10 \mathrm{~min}$ at $4^{\circ} \mathrm{C}$ (Sigma 3-18 K; Sigma Laborzentrifugen, Germany) for later analysis.

2.4. Antioxidant Activity and Total Phenolic Content. Nondigested table olives (test matrix (TM)) and RF were extracted as described by previous authors [9]. Briefly, $2 \mathrm{~g}$ of fresh sample was mixed with $10 \mathrm{~mL}$ of $\mathrm{MeOH} /$ water $(80: 20$ $\mathrm{v} / \mathrm{v})+1 \% \mathrm{HCl}$. This mixture was sonicated for $15 \mathrm{~min}$, and then, it was left overnight at $4^{\circ} \mathrm{C}$. The next day, samples were sonicated again for $15 \mathrm{~min}$ and centrifuged at 10,000 rpm for $10 \mathrm{~min}$ at $4^{\circ} \mathrm{C}$ (Sigma $3-18 \mathrm{~K}$; Sigma Laborzentrifugen, Germany).

Antioxidant activity of TM, SF, and RF was measured using three assays: (i) $\mathrm{ABTS}^{+\bullet}$ as reported in [10], (ii) $\mathrm{DPPH}^{\bullet}$ as reported in [11], and (iii) FRAP following protocol in [12]. Additionally, TPC assay was carried out as in [13]. All analyses were performed using an UV-visible spectrophotometer (Helios Gamma model, UVG 1002E). Results for antioxidant activity were quantified using calibration curves with Trolox and expressed as mmol Trolox kg ${ }^{-1}$ of table olives. TPC calibration curves were obtained with gallic acid, and results were expressed as gallic acid equivalents (GAE), $\mathrm{g} \mathrm{kg}^{-1}$ of table olives.

TPC bioaccessibility, expressed as the percentage of total polyphenols liberated from the TM after the gastrointestinal digestion, was calculated as previously reported by [14]:

$$
\text { Bioaccessibility }(\%)=\mathrm{CF} / \mathrm{CI} \times 100 \text {, }
$$

where $\mathrm{CF}$ is the polyphenols concentration in the $\mathrm{SF}$ fraction and $\mathrm{CI}$ is the initial polyphenols concentration in undigested flesh table olives.
2.5. Statistical Analysis. One-way analysis of variance (ANOVA) was carried out to study the effect of RDI treatment, and then, Tukey's multiple range test was used to compare the means. The standard deviation (SD) of the mean is used to perform Tukey's test; therefore, the SD values were not included in tables to avoid repetition of the data and to make tables easier to understand. Statistical differences were considered significant at three levels: (i) $p<0.05\left({ }^{*}\right)$, (ii) $p<0.01\left(^{* *}\right)$, and (iii) $p<0.001\left(^{* * *}\right)$. An XLSTAT (2016.02.27444 version, Addinsoft) was used to perform all statistical analysis.

\section{Results and Discussion}

3.1. Irrigation. As can be seen in Table 1, different levels of water stress were reached by olive trees. In experiment $A$, it could be found that A0 presented the lowest $\Psi_{\text {int }}$ because it was not submitted to stress (control treatment). The A1 (moderate deficit irrigation) and A2 (severe deficit irrigation during short time) trees had intermediate and equivalent $\Psi_{\text {int }}$ values, while $\mathrm{A} 3$ (severe deficit irrigation during long time) trees presented the highest $\Psi_{\text {int }}$ value. In experiment B, although $\mathrm{B} 0$ (control) was fully irrigated, it could be seen that its $\Psi_{\text {int }}$ value was higher than that of B1 (moderate deficit irrigation during short time before harvest). This experimental fact can be justified because even though researchers can control the applied water volume, other natural factors such as overall weather (e.g., rain) or soil differences among areas of the same field can also significantly affect $\Psi_{\text {int }}$. Finally, B2 presented the highest $\Psi_{\text {int }}$ value due to water stress was moderate but during a long time before harvest.

3.2. Antioxidant Activity and Total Phenolic Content. Results of antioxidant activity and TPC of table olives under study are shown in Table 2 . In experiment A, no statistical differences were found among irrigation treatments in the antioxidant activity of the TM. Regarding $\mathrm{ABTS}^{+\bullet}$ assay, in the $\mathrm{SF}$ and total $(\mathrm{SF}+\mathrm{RF})$ fractions, it was found that the higher the stress, the higher the antioxidant potential. With respect to the percentage of variation (\% var), after gastrointestinal in vitro digestion, for $\mathrm{ABTS}^{+}$, it was found a decrease of $\sim 76 \%$ and the smallest decrease was found for A3 table olives (those with the highest water stress). Regarding $\mathrm{DPPH}^{\bullet}$, in the SF and total fractions, the highest value was found on A1 at a moderate stress level, while olives from the A3 treatment (highest water stress) showed a decrease on $\mathrm{DPPH}^{\bullet}$ in comparison to control (A0). The $\mathrm{DPPH}^{\bullet} \%$ var was higher than that of $\mathrm{ABTS}^{+\bullet}$, with a $\sim 95 \%$ decrease. FRAP assay did not show statistical differences in any fraction under study, and the $\%$ var was $\sim 92 \%$. Concerning TPC, only SF showed statistical differences between irrigation treatments, and a small increase (2.8\%) was found between control and three RDI table olives. A decrease of $\sim 82 \%$ was found with respect to the variation percentage.

Regarding experiment B, TM showed statistical differences on $\mathrm{DPPH}^{\bullet}$ and FRAP assays, as well as on TPC. For $\mathrm{DPPH}^{\bullet}$ and TPC, both RDI treatments showed higher values than control, being the highest B1, while in FRAP assay, B1 
TABle 2: Antioxidant activity (ABTS+•, DPPH, and FRAP) and Total Phenolic Content (TPC) of "Manzanilla" table olives before and after gastrointestinal in vitro simulation digestion of experiment $\mathrm{A}$ and experiment $\mathrm{B}$.

\begin{tabular}{|c|c|c|c|c|c|c|c|c|c|c|c|c|c|c|c|c|c|c|c|c|}
\hline \multicolumn{16}{|c|}{ Antioxidant activity (mmol trolox eq kg-1) } & \multirow{2}{*}{\multicolumn{5}{|c|}{ TPC $\left(\mathrm{g} \mathrm{GAE} \mathrm{kg}^{-1}\right)$}} \\
\hline & \multicolumn{5}{|c|}{ ABTS+• } & \multicolumn{5}{|c|}{ DPPH• } & \multicolumn{5}{|c|}{ FRAP } & & & & & \\
\hline & $\mathrm{TM}$ & SF & $\mathrm{RF}$ & Total & $\%$ var & $\mathrm{TM}$ & SF & $\mathrm{RF}$ & Total & $\%$ var & TM & SF & $\mathrm{RF}$ & Total & $\%$ var & TM & SF & $\mathrm{RF}$ & Total & $\%$ var \\
\hline \multicolumn{20}{|c|}{ Experiment A } & \\
\hline A0 & 6.61 & $\begin{array}{c}1.34 \\
\mathrm{~b}^{\ddagger}\end{array}$ & 0.11 & $\begin{array}{c}1.45 \\
\mathrm{~b}\end{array}$ & -78.1 & 12.1 & $\begin{array}{c}0.51 \\
\mathrm{ab}\end{array}$ & 0.08 & $\begin{array}{c}0.59 \\
\mathrm{ab}\end{array}$ & -95.1 & 15.4 & 1.06 & 0.20 & 1.25 & -91.9 & 6.17 & $\begin{array}{c}0.70 \\
\mathrm{~b}\end{array}$ & 0.42 & 1.13 & -81.7 \\
\hline A1 & 7.48 & $\begin{array}{c}1.56 \\
\mathrm{ab}\end{array}$ & 0.13 & $\begin{array}{c}1.69 \\
\mathrm{ab}\end{array}$ & -77.4 & 13.0 & $\begin{array}{c}0.60 \\
\mathrm{a}\end{array}$ & 0.26 & $\begin{array}{c}0.87 \\
\mathrm{a}\end{array}$ & -93.3 & 16.0 & 0.75 & 0.22 & 0.97 & -93.9 & 6.46 & $\begin{array}{c}0.72 \\
\mathrm{a}\end{array}$ & 0.33 & 1.05 & -83.7 \\
\hline A2 & 7.07 & $\begin{array}{c}1.43 \\
\mathrm{ab}\end{array}$ & 0.11 & $\begin{array}{c}1.53 \\
b\end{array}$ & -78.4 & 12.5 & $\begin{array}{c}0.37 \\
b c\end{array}$ & 0.09 & $\begin{array}{c}0.47 \\
\mathrm{ab}\end{array}$ & -96.2 & 14.8 & 0.89 & 0.23 & 1.12 & -92.4 & 5.90 & $\begin{array}{c}0.72 \\
\mathrm{a}\end{array}$ & 0.28 & 0.99 & -83.2 \\
\hline $\mathrm{A} 3$ & 7.19 & $\begin{array}{c}1.71 \\
\mathrm{a}\end{array}$ & 0.25 & $\begin{array}{c}1.98 \\
\mathrm{a}\end{array}$ & -72.5 & 11.2 & $\begin{array}{c}0.25 \\
c\end{array}$ & 0.00 & $\begin{array}{c}0.19 \\
\mathrm{~b}\end{array}$ & -98.3 & 15.5 & 0.95 & 0.22 & 1.17 & -92.5 & 5.47 & $\begin{array}{c}0.72 \\
\mathrm{a}\end{array}$ & 0.30 & 1.02 & -81.4 \\
\hline \multicolumn{20}{|c|}{ Experiment B } & \\
\hline B0 & 8.74 & 1.23 & 0.05 & 1.29 & -85.2 & $\begin{array}{c}7.31 \\
\mathrm{c}\end{array}$ & 0.47 & 0.00 & 0.47 & -93.6 & $\begin{array}{c}19.1 \\
\mathrm{a}\end{array}$ & 0.99 & 0.22 & 1.21 & -93.7 & $\begin{array}{c}5.46 \\
\mathrm{c}\end{array}$ & 0.72 & 0.23 & 0.95 & -82.6 \\
\hline B1 & 9.41 & 1.54 & 0.07 & 1.62 & -82.8 & $\begin{array}{c}9.64 \\
\mathrm{a}\end{array}$ & 0.34 & 0.00 & 0.34 & -96.5 & $\begin{array}{c}17.8 \\
\mathrm{~b}\end{array}$ & 1.12 & 0.24 & 1.36 & -92.4 & $\begin{array}{c}5.90 \\
\mathrm{a}\end{array}$ & 0.72 & 0.34 & 1.05 & -82.2 \\
\hline B2 & 9.34 & 1.26 & 0.06 & 1.32 & -85.9 & $\begin{array}{c}8.62 \\
b\end{array}$ & 0.31 & 0.00 & 0.31 & -96.4 & $\begin{array}{c}19.3 \\
\mathrm{a}\end{array}$ & 1.12 & 0.24 & 1.36 & -93.0 & $\begin{array}{c}5.83 \\
\mathrm{~b}\end{array}$ & 0.72 & 0.24 & 0.96 & -83.5 \\
\hline
\end{tabular}

${ }^{\dagger} \mathrm{NS}=$ not significant at $p<0.05 ;{ }^{*},{ }^{* *}$, and ${ }^{* * *}$ significant at $p<0.05,0.01$, and 0.001 , respectively. ${ }^{*}$ Values followed by the same letter within the same column were not significantly different $(p<0.05)$, according to Tukey's least significant difference test. Note. TM: test matrix; SF: soluble fraction, liquid; RF: residual fraction, solid; Total: SF + RF; \% var (\% variation): percentage of variation between the initial values and the values obtained after digestion.

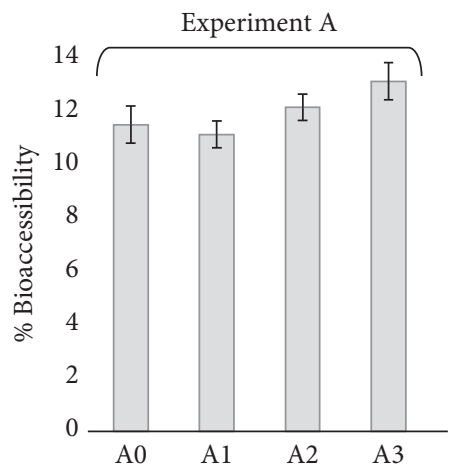

(a)

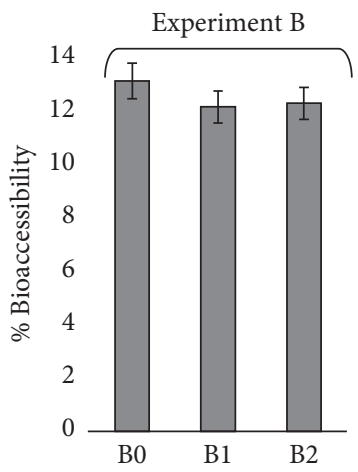

(b)

FIgURE 1: Total phenol content bioaccessibility after gastrointestinal in vitro digestion simulation of "Manzanilla" table olives of experiment A (a) ( $\square$ ) and experiment B (b) ( $\square$ ). Columns followed by the same letter within the same experiment were not significantly different $(p<0.05)$, according to Tukey's least significant difference test.

was the treatment that presented the lowest value. No statistical differences between treatments were found after gastrointestinal in vitro digestion simulation for this experiment. For $\mathrm{ABTS}^{+\bullet}$, it was found an average of $1.4 \mathrm{mmol}$ Trolox $\mathrm{kg}^{-1}$ of total fraction and a $\%$ var of $\sim-85 \%$. For $\mathrm{DPPH}^{\bullet}$ values showed an average of $0.4 \mathrm{mmol}$ Trolox $\mathrm{kg}^{-1}$ for total fraction with a $\%$ var of $\sim-95 \%$. With respect to FRAP assay, total fraction showed an average of $1.31 \mathrm{mmol}$ Trolox $\mathrm{kg}^{-1}$ and a $\%$ var of $\sim-93 \%$. Finally, average TPC was $0.99 \mathrm{~g} \mathrm{GAE} \mathrm{kg}^{-1}$ and TPC had a \% var of $\sim-83 \%$.

Although no statistical differences between irrigation treatments were found on RF, some assays showed higher values than control, such as $\mathrm{DPPH}^{\bullet}\left(\sim 0.4 \mathrm{mmol}\right.$ Trolox kg $\left.{ }^{-1}\right)$ and TPC $\left(\sim 0.3 \mathrm{~g} \mathrm{GAE} \mathrm{kg}^{-1}\right)$. Those values could be relevant because they might indicate that there are still antioxidant and polyphenolic compounds that could be metabolized by the colon microflora, and thus, it points to a potential increase in bioavailability. Therefore, RF values found on table olives coming from deficit irrigation strategies indicated that stress caused on plant could affect the final bioavailability of antioxidants and polyphenols increasing the content of these compounds available for human absorption [15].

Figure 1 represents the percentage of bioaccessibility of TPC after the gastrointestinal in vitro digestion simulation. In both experiments, no statistically significant differences were found among irrigation treatments. In experiment $\mathrm{A}$, A0 presented $11.5 \%, \mathrm{~A} 1,11.1 \%, \mathrm{~A} 2,12.1 \%$, and $\mathrm{A} 3,13.1 \%$ of TPC bioaccessibility. In experiment $\mathrm{B}$, control (B0) was 
13.2\% bioaccessible, while B1 and B2 treatments showed 12.2 and $12.3 \%$ of TPC bioaccessibility, respectively.

The decrease on antioxidant capacity and phenolic compounds content may be related to their degradation. A high proportion of table olive polyphenols are very susceptible to chemical degradation when they are submitted to the acidic conditions of digestion [15]. It was formerly described the polyphenolic profile of hydroSOStainable table olives of the current research [3], and it was found an increase of oleuropein, comselogoside, and verbascoside on A1 treatment as compared with control, as well as an increase of elenoic acid glucoside, oleuropein, and comselogoside regarding RDI treatments of experiment B. Beside this increases, it was previously reported that only $25 \%$ of oleuropein (one of the most important polyphenols in table olives) was stable during digestion, as well as only $20 \%$ of comselogoside and elenoic acid derivatives [15]. Flavonoids, verbascoside, and hydroxytyrosol derivatives also presented a small TPC bioaccessibility in a research conducted with three table olives cultivars [14]. Flavonoids are not very soluble in either organic or aqueous solvents and are usually present in foods in combination with sugars in the form of glycosides [16], so it is possible that higher concentrations that were found on RDI table olives on some flavonoids such as luteolin [3] would probably not have been extracted from the olive pulp during the in vitro digestion simulation.

Similar results, to the ones reported in the current study, have been previously reported in "Cornezuelo" table olives [15]. For instance, it was found a high decrease of $\mathrm{DPPH}^{\bullet}$ and $\mathrm{ABTS}^{+}$after gastrointestinal digestion simulation and also a decrease of $75 \%$ of TPC.

Several factors can influence the phenolic bioaccessibility. The digestion process could produce changes on polyphenol composition modifying their original profile. The food matrix where polyphenols are found could also influence the extraction [16]. It has been previously reported that the fermentation process suffered during table olives preparation and the olive cultivar could influence the final polyphenol extraction [14].

There is lack of information about the how the stress suffered by plants is related to the later metabolism of the compounds by human digestive apparatus. In the present research, the water stress suffered by olive trees due to irrigation strategies did not provide significant differences among treatments on final TPC and bioaccessibility in both experiments. It has been demonstrated that it is possible to save irrigation water without having significant effect on the final polyphenolic compounds available for human absorption. Daily intake of polyphenolic compounds is very important because of their associated health benefits. Higher total consumption of $600 \mathrm{mg}$ per day would provide a protective effect against chronic diseases [17]. Consequently, eating 10 hydroSOStainable table olives per day $(40 \mathrm{mg}$ of bioaccessible polyphenols) would contribute to a $\sim 7 \%$ of this total polyphenol intake recommendation.

\section{Conclusions}

This is the first study investigating the effect of gastrointestinal in vitro digestion simulation on antioxidant potential and total polyphenol content, and its bioaccessibility of table olives submitted to regulated deficit irrigation strategies. Water stress was applied during two growing stages, experiment A: the pit hardening stage and experiment B: during the rehydration phase. Results showed that, in experiment B, antioxidants and polyphenols were not affected by the stress after gastrointestinal in vitro digestion simulation, while in experiment A, regarding TPC, $\mathrm{ABTS}^{+}$, and $\mathrm{DPPH}^{\bullet}$, slight differences were found among treatments. In general, a total of $\sim 1 \mathrm{~g} \mathrm{GAE} \mathrm{kg}^{-1}$ was extracted after digestion, indicating that the bioaccessibility of the TPC of both control and hydroSOStainable table olives was $\sim 12 \%$. Therefore, the daily intake of 10 hydroSOStainable table olives entails the intake of $40 \mathrm{mg}$ of "bioaccessible" polyphenols and involve the daily of $\sim 7 \%$ of polyphenols intake recommendation for protective effect against chronic diseases.

\section{Data Availability}

The data used to support the findings of this study are included within the article.

\section{Conflicts of Interest}

The authors declare that they have no conflicts of interest.

\section{Acknowledgments}

This study has been funded by (Ministerio de Ciencia, Innovación (MCI) Agencia Estatal de Investigación (AEI) and Fondo Europeo de Desarrollo Regional (FEDER)) through a coordinated research project (hydroSOS mark) including the Universidad Miguel Hernández de Elche (AGL2016-75794-C4-1-R, hydroSOS foods) and the Universidad de Sevilla (AGL2016-75794-C4-4-R) (MCI/AEI/ FEDER, UE). Author Marina Cano-Lamadrid was funded by a FPU grant from the Spanish Ministry of Education (FPU15/02158).

\section{References}

[1] C. Dinnella, P. Minichino, A. M. D’Andrea, and E. Monteleone, "Bioaccessibility and antioxidant activity stability of phenolic compounds from extra-virgin olive oils during in vitro digestion," Journal of Agricultural and Food Chemistry, vol. 55, no. 21, pp. 8423-8429, 2007.

[2] I. D'Antuono, A. Garbetta, B. Ciasca et al., "Biophenols from table olive cv bella di Cerignola: chemical characterization, bioaccessibility, and intestinal absorption," Journal of Agricultural and Food Chemistry, vol. 64, no. 28, pp. 5671-5678, 2016.

[3] L. Sánchez-Rodríguez, M. Cano-Lamadrid, Á. A- CarbonellBarrachina, A. Wojdyło, E. Sendra, and F. Hernández, "Polyphenol profile in manzanilla table olives as affected by water deficit during specific phenological stages and Spanishstyle processing," Journal of Agricultural and Food Chemistry, vol. 67, no. 2, pp. 661-670, 2019.

[4] M. H. Ahmad-Qasem, J. Cánovas, E. Barrajón-Catalán, J. E. Carreres, V. Micol, and J. V. García-Pérez, "Influence of olive leaf processing on the bioaccessibility of bioactive 
polyphenols," Journal of Agricultural and Food Chemistry, vol. 62, no. 26, pp. 6190-6198, 2014.

[5] M. J. Martín-Palomo, M. Corell, I. Girón et al., “Absence of yield reduction after controlled water stress during prehaverst period in table olive trees," Agronomy, vol. 10, no. 2, p. 258, 2020.

[6] B. J. Myers, "Water stress integral-a link between short-term stress and long-term growth," Tree Physiology, vol. 4, no. 4, pp. 315-323, 1988.

[7] L. Sánchez-Rodríguez, L. Lipan, L. Andreu et al., "Effect of regulated deficit irrigation on the quality of raw and table olives," Agricultural Water Management, vol. 221, pp. 415421, 2019.

[8] M. Minekus, M. Alminger, P. Alvito et al., "A standardised staticin vitrodigestion method suitable for food-an international consensus," Food and Function, vol. 5, no. 6, pp. 1113-1124, 2014.

[9] M. Cano-Lamadrid, F. Hernández, M. Corell et al., "Antioxidant capacity, fatty acids profile, and descriptive sensory analysis of table olives as affected by deficit irrigation," Journal of the Science of Food and Agriculture, vol. 97, no. 2, pp. 444-451, 2017.

[10] R. Re, N. Pellegrini, A. Proteggente, A. Pannala, M. Yang, and C. Rice-Evans, "Antioxidant activity applying an improved ABTS radical cation decolorization assay," Free Radical Biology and Medicine, vol. 26, no. 9-10, pp. 1231-1237, 1999.

[11] W. Brand-Williams, M. E. Cuvelier, and C. Berset, "Use of a free radical method to evaluate antioxidant activity," LWT_Food Science and Technology, vol. 28, no. 1, pp. 25-30, 1995.

[12] I. F. F. Benzie and J. J. Strain, "The ferric reducing ability of plasma (FRAP) as a measure of "antioxidant power": the FRAP assay," Analytical Biochemistry, vol. 239, no. 1, pp. 70-76, 1996.

[13] X. Gao, M. Ohlander, N. Jeppsson, L. Björk, and V. Trajkovski, "Changes in antioxidant effects and their relationship to phytonutrients in fruits of sea buckthorn (Hippophae rhamnoides L.) during maturation," Journal of Agricultural and Food Chemistry, vol. 48, no. 5, pp. 1485-1490, 2000.

[14] I. D'Antuono, A. Bruno, V. Linsalata et al., "Fermented Apulian table olives: effect of selected microbial starters on polyphenols composition, antioxidant activities and bioaccessibility," Food Chemistry, vol. 248, pp. 137-145, 2018.

[15] M. P. Fernández-Poyatos, A. Ruiz-Medina, and E. J. LlorentMartínez, "Phytochemical profile, mineral content, and antioxidant activity of Olea europaea L. Cv. Cornezuelo table olives. Influence of in vitro simulated gastrointestinal digestion," Food Chemistry, vol. 297, Article ID 124933, 2019.

[16] F. A. Tomás-Barberán, "Los polifenoles de los alimentos y la salud," Alimentación, Nutrición Y Salud, vol. 10, no. 2, pp. 41-53, 2006.

[17] I. Navarro González, M. J. Periago, and F. J. García Alonso, "Estimación de la ingesta diaria de compuestos fenólicos en la población española," Revista Española de Nutrición Humana Y Dietética, vol. 21, no. 4, pp. 320-326, 2017. 